ISSN 2447-9071

doi https://doi.org/10.36414/rbmc.v6i15.48

Contato para correspondência: Hermínio Maurício da Rocha Sobrinho

E-mail:

herminio.sobrinho@gmail.com

Conflito de interesse: Não

Financiamento: Recursos próprios

Recebido: 20/06/2020

Aprovado: 09/07/2020

\section{A laserterapia no tratamento da acne vulgar}

\section{Laser terapy in the treatment of vulgar acne}

Tatiane Alves Saraiva', Luana da Silva Souza', Kleber França Costa',

Patrícia Luz Almeida Leroy ${ }^{1}$, Hermínio Maurício da Rocha Sobrinho ${ }^{1,2}$

1 Universidade Estadual de Goiás - UEG

2 Pontifícia Universidade Católica de Goiás - PUC Goiás

\section{Resumo}

Aacneéuma doença inflamatória crônica da unidade pilossebácea eacomete aproximadamente $80 \%$ da população jovem. Há inúmeros tratamentos para a acne vulgar, entretanto, estudos têm demonstrado que o laser é uma modalidade alternativa e efetiva para tratamento da acne vulgar, que tem se mostrado como uma alternativa às medicações tópicas e orais. Esta pesquisa é caracterizada como revisão bibliográfica narrativa. O recorte temporal desta pesquisa foi de estudos publicados no período de2004 a 2019. Oobjetivo desteestudo foidescreveros principaismecanismos deação, efeitos biológicos e os benefícios do uso do laser terapêutico no tratamento da acne vulgar. O laser terapêutico atua nos principais fatores fisiopatológicos desta afecção, inclusive podendo minimizar as lesões inflamatórias da acne. Estudos demonstraram que o tratamento da acne vulgar com laser foi um método eficaz para a redução do número de lesões de acne graus Il e lll e que apresenta mínimos efeitos adversos quando comparado com tratamento medicamentoso. Esse fato confere ao laser uma opção real de tratamento, principalmenteparaos pacientes com contraindicação aosoutros métodos de tratamento. Embora sejam eficazes, em geral, os lasers diferem em termos de efeitos colaterais e resultados clínicos, dependendo do fototipo de pele e do tipo de cicatriz de acne do paciente, cabendo ao profissional escolher o melhor tipo delaserpara cada tratamento deacne. Estudos clínicos rigorosose contínuos paraasnovas modalidades de laser que entram no mercado são críticos para garantir sua segurança e eficácia no tratamento da acne e no desenvolvimento de protocolos terapêuticos apropriados.

Palavras-Chave: Acne vulgar, Fototerapia, Laser, Laserterapia.

\begin{abstract}
Acne is a chronic inflammatory disease of the pilosebaceous unit and affects approximately $80 \%$ of theyoung population. There arenumerous treatments for acne vulgaris, however, studies have shown that laser is an alternative and effective modality for treating acne vulgaris, which has proven to be an alternative to topical and oral medications. This study is characterized as narrative bibliographic review. The time frame of this research was from studies published in the period from 2004 to 2019. The objective of this study was to describe the main mechanisms of action, biological effects and the benefits of using therapeutic laser in the treatment of acne vulgaris. The laser acts on the main pathophysiological factors of this condition, including being able to minimize the inflammatory lesions of acne. Studies have shown that laser treatment of acne vulgaris has been an effective method for reducing the number of grade Il and III acne lesions and has minimal adverse effects when compared to drug treatment. This gives the laser a real treatment option, especially for patients who are contraindicated to other treatment methods. Although they are generally effective, lasers differ in terms of side effects and clinical results, depending on the skin phototype and the type of acne scar of the patient, and it is up to the professional to choose the best type of laser for each acne treatment. Careful and continuous clinical studies for the new laser modalities that enter the market are critical to ensure their safety and effectiveness in the treatment of acne and in the development of appropriate therapeutic protocols.
\end{abstract}

Keywords: Acne vulgaris; Laser; Laser therapy; Phototherapy. 


\section{Introdução}

A acne é uma dermatose inflamatória da unidade pilossebácea, cuja patogênese é multifatorial. Os principais fatores contribuintes para seu desenvolvimento incluem hiperqueratinização folicular, aumento da produção de sebo pelas glândulas sebáceas, colonização bacteriana do folículo piloso pelo Propionibacterium acnes (P. acnes) e liberação de mediadores inflamatórios na unidade pilossebácea e na derme adjacente'

Embora a acne não esteja associada a situações de morbidade severa, incapacidade física ou mortalidade, tem significativas repercussões físicas, psicológicas e sociais, que podem ser minimizadas com um tratamento precoce e adequado ${ }^{2}$. A presença de cicatrizes de acne tem um impacto profundamente negativo na qualidade de vida de um indivíduo, pois induzem a perda de confiança em sua aparência física, sentimentos de exclusão pelo próximo e depressão, o que afeta sua vida profissional e pessoal do indivíduo ${ }^{3}$.

Há diversos tratamentos disponíveis para a acne vulgar, entretanto, existem casos de difícil manejo, principalmente os graus mais severos, em que, frequentemente, apesar de terapias novas, as lesões continuam surgindo. A terapia tradicional inclui medicamentos tópicos e orais (retinoides e antibióticos), que nem sempre são eficazes e muitas vezes provocam resistência bacteriana e efeitos colaterais ${ }^{1,4}$. Diante disso, tratamentos com base nos lasers têm se tornado, nos últimos anos, alternativa às medicações tópicas e orais, pois podem reduzir as lesões inflamatórias da acne, evitar cicatrizes, favorecer o rejuvenescimento cutâneo, e ainda, atuar nos principais fatores fisiopatológicos da acne ${ }^{5-7}$.

O uso do laser no tratamento da acne inflamatória cresceu ultimamente devido à facilidade desse tipo de terapia, a sua eficácia clínica e aos mínimos efeitos adversos ${ }^{6,7}$. Diante disso, o presente trabalho teve por objetivos descrever os principais mecanismos de ação, efeitos biológicos e os benefícios do uso do laser terapêutico no tratamento da acne vulgar.

\section{Métodos}

Esta pesquisa constitui uma revisão bibliográfica narrativa. Para a busca dos estudos foram utilizadas as bases de dados virtuais: Portal de Periódicos da Capes, Scientific Electronic Library Online (Scielo) e US National Library of Medicine (Pubmed) e Google Acadêmico, utilizando-se os seguintes Descritores em Ciências da Saúde (DeCS), isolados e/ou combinados: Acne vulgar, Laser, Laserterapia, fototerapia, nos idiomas português, inglês e espanhol, publicados no período do ano 2004 ao de 2019. Foram incluídos estudos disponíveis, nas bases de dados eletrônicas utilizadas, com texto completo, dentro do período temporal determinado e que apresentaram conteúdos com- patíveis com os objetivos propostos, sendo encontrados 109 artigos. Deste total de estudos, foram selecionados 63 artigos, sendo excluídos 36 estudos, os quais foram publicados fora do período temporal estabelecido, os duplicados, aqueles cujos conteúdos não eram condizentes com os objetivos propostos e os estudos que não estavam disponíveis na íntegra nas plataformas virtuais utilizadas.

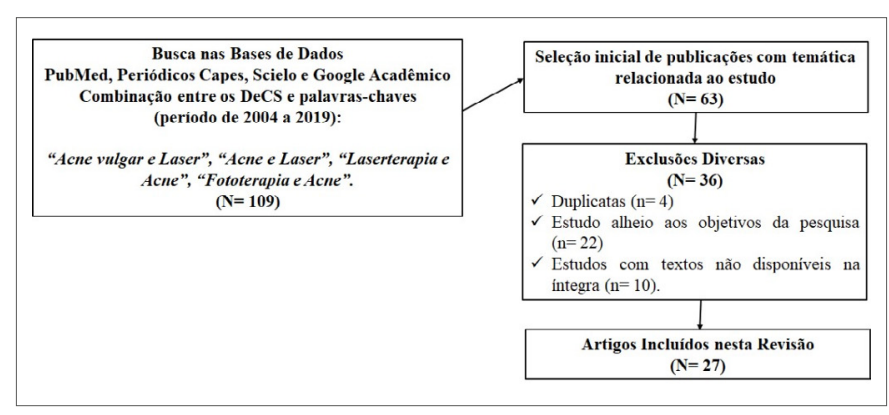

Figura 1. Algoritmo adotado para a busca e seleção de artigos na elaboração desta revisão.

\section{Resultados e Discussão}

A acne é uma enfermidade crônica de etiologia multifatorial que causa obstrução e inflamação da unidade pilossebácea. A partir do estímulo das glândulas sebáceas, por fatores ambientais (infecção bacteriana) ou endógenos (hormônios), há um aumento da secreção de sebo levando a hiperqueratinização com obstrução do canal folicular. Este processo causa uma reação inflamatória local, induzindo o aparecimento das lesões acneicas ${ }^{4}$.

$\mathrm{Na}$ adolescência, é muito frequente a ocorrência dessa afecção, podendo ocorrer também em outras fases da vida, sendo mais comum em homens, porém atingindo também as mulheres. Em alguns indivíduos a acne pode evoluir para formas mais graves, isso pode gerar isolamento social e depressão, pois altera a autoestima, e consequentemente afeta a qualidade de vida do indivíduo ${ }^{8}$.

\section{Etiopatogenia da Acne}

Compreende-se que a patogênese da acne esteja ligada a quatro fatores: (1) obstrução do folículo piloso, secundário à descamação anormal dos queratinócitos foliculares; (2) aumento da produção sebácea; (3) proliferação da bactéria anaeróbica Propionibacterium acnes (P.acnes) e (4) desencadeamento de resposta inflamatória induzida pelo P. acnes ${ }^{4}$.

Diferentemente dos pacientes que apresentam acne, os queratinócitos foliculares de indivíduos saudáveis são descamados como células isoladas e carregados do lúmen folicular para 
fora através do sebo secretado pelas glândulas sebáceas. Já em pacientes que apresentam acne, os queratinócitos descamamse de forma densamente agrupada, formando um tampão que obstrui o infundíbulo folicular. É possível que essa alteração possa estar relacionada a mudanças na composição sebácea por redução na quantidade do ácido linoleico, ou quando os hormônios andrógenos induzem a proliferação celular, ou até mesmo por haver aumento na concentração de Interleucina-1a (IL-1a) secretada dos queratinócitos foliculares ${ }^{1,4}$.

O microcomedão é formado pelos fatores descritos acima, sendo assim precursor das outras lesões da acne. Isso acontece devido ao bloqueio no fluxo do sebo, dessa forma obstrui o folículo e causa o acumulo de fragmentos celulares, bactérias e lipídeos no lúmen folicular ${ }^{1,4}$.

\section{Manifestações Clínicas}

A acne é classificada de acordo com seu tipo de lesão, conforme o quadro 1. As lesões podem ser do tipo comedônica, pápulo-pustulosa e nódulo-cística'.

Quadro 1. Tipos de lesões na Acne vulgar.

\begin{tabular}{|c|c|}
\hline Lesões Não Inflamatórias & Lesões Inflamatórias \\
\hline $\begin{array}{l}\text { Comedão fechado: primeira } \\
\text { lesão elementar da acne, o qual } \\
\text { obstrui o folículo piloso por } \\
\text { sebo e queratina. Levemente } \\
\text { ressaltado na pele e apresenta- } \\
\text {-se como pequeno grão miliar. } \\
\text { Comedão aberto ou "cravo": } \\
\text { lesão decorrente da dilatação } \\
\text { do orifício folicular e oxidação } \\
\text { do conteúdo folicular (sebo, } \\
\text { queratina). }\end{array}$ & $\begin{array}{l}\text { Pápula: lesão sólida elevada e eritematosa, com } \\
\text { presença de edema, com diâmetro menor que } \\
10 \mathrm{~mm} \text {. } \\
\text { Pústula: vesículas contendo pus, com diâmetro } \\
\text { menor que } 10 \mathrm{~mm} \text {. } \\
\text { Nódulo: são lesões sólidas que se estendem } \\
\text { na derme ou no tecido subcutâneo, podendo } \\
\text { atingir até } 2 \mathrm{~cm} \text {. } \\
\text { Cisto: lesão com conteúdo líquido, semissólido } \\
\text { ou pastoso, pode se apresentar com recapsu- } \\
\text { lações. } \\
\text { Cicatriz: lesão fibrosa, em consequência da } \\
\text { reação inflamatória, há destruição do folículo pi- } \\
\text { lossebáceo, originando uma depressão irregular } \\
\text { coberta de pele atrófica. }\end{array}$ \\
\hline
\end{tabular}

Fonte: Figueiredo'; Paschoal \& Ismael ${ }^{4}$

A acne inflamatória e a não inflamatória podem formar cicatrizes que são o resultado de danos ao colágeno dérmico durante a cicatrização das lesões elementares ${ }^{3,6,9}$.

\section{Terapias para o tratamento da Acne Vulgar}

As terapias para o tratamento da acne vulgar visam a melhora no aspecto geral da pele e contenção do grau de acometimento desta afecção dermatológica. O tratamento escolhido sob avaliação é individual e varia de acordo com o grau de acometimento desta afeç̧ão e a sua tipologia9. O tratamento pode ser dividido em:

- Profilático: cuidados higiênicos e alimentares;

- Medicamentoso/Farmacológico: utiliza fármacos sob prescrição médica, tais como, anti-inflamatórios, antibióticos, corticoides, isotretinoína, entre outros;

- Estético/terapêutico: envolve a higienização e cuidados com a pele, o uso de recursos terapêuticos para eliminar ou reduzir os fatores etiopatogênicos da acne. Podendo se utilizar, por exemplo, a fototerapia (laser e luz pulsada), peelings, radiofrequência, entre outros $\mathrm{s}^{9,10}$. Os peelings mecânicos e químicos são realizados a fim de abrandar manchas e cicatrizes superficiais provenientes da acne. E os lasers e a fototerapia (LED, Luz Intensa Pulsada, UVA/UVB, terapia fotodinâmica) são indicados por suas propriedades anti-inflamatória e bactericida, e ainda, pela capacidade de reorganizar o colágeno da pele $e^{9,10}$.

\section{Laserterapia}

A palavra laser é uma sigla inglesa (LASER - Light Amplification by Stimulated Emission of Radiation) que significa amplificação da luz por emissão estimulada da radiação. 0 laser é conhecido por ser uma fonte de luz coerente, sendo assim, pode atingir pontos específicos da pele ${ }^{11}$. Atualmente, os tratamentos baseados em luz para acne inflamatória leve a moderada incluem uma variedade de tecnologias de luz de alta irradiância, como luz intensa pulsada, fotobiomodulação (Laser e LED) e terapia fotodinâmica. Os níveis de irradiância empregados pelos lasers nos tratamentos de fotobiomodulação (processo baseado na interação de fótons com moléculas e células provocando alterações biológicas) são consideravelmente mais baixos do que os dos mecanismos ablativos tradicionais e funcionam ativando vias fotoquimicamente em seus tecidos-alvo. Para ter algum efeito biológico em um organismo vivo, os fótons terapêuticos devem primeiro ser absorvidos por um cromóforo molecular ou fotoaceptor, como porfirinas, flavinas, melanina ou outras entidades de absorção de luz no tecido-alvo ${ }^{12}$.

A ação do laser varia em função do comprimento de onda; duração do impulso; tamanho, tipo e profundidade do alvo e interação entre a luz emitida pelo laser e o alvo determinado. $\mathrm{O}$ cromóforo é um grupo de átomos que dá cor a uma substância e absorve luz com um comprimento de onda específico no espectro do visível. No caso da pele os principais cromóforos são a melanina, hemoglobina, carotenos, flavoproteínas, porfirinas e moléculas de água ${ }^{5,12,14}$.

A absorção de energia térmica pelos cromóforos presentes na epiderme/derme estimula o remodelamento da matriz ex- 
tracelular, a produção de colágeno e elastina e, dependendo do comprimento de onda de luz selecionado, a redução de pigmento e de eritema, reduzindo o processo inflamatório e estimulando a cicatrização tecidual nas lesões de acne vulgar ${ }^{7,12}$.

O laser atua aquecendo a região de tratamento fazendo com que as glândulas sebáceas diminuam sua atividade produtora e secretora de sebo, melhorando a acne. Devido a esse aquecimento contribui com a formação de colágeno melhorando as cicatrizes causadas pela acne ${ }^{12,13}$.

A partir do momento em que a luz atinge a pele, ocorrem três processos de interação do fóton com estruturas do tecido: reflexão, dispersão e absorção $0^{4,18}$. A radiação emitida pelos lasers de baixa potência possui efeitos analgésicos, anti-inflamatórios e cicatrizantes, sendo estes os fatores responsáveis pelos quais o mesmo tem sido utilizado frequentemente no processo de reparo tecidual, devido as baixas densidades de energia usadas e comprimentos de onda capazes de penetrar nos tecidos. Quando o laser interage com células e tecidos, algumas funções celulares são estimuladas, levando a ativação de linfócitos e mastócitos da pele, o aumento na produção de ATP mitocondrial e a proliferação de vários tipos de células cutâneas (macrófagos, células dendríticas, fibroblastos, etc) desencadeando efeitos anti-inflamatórios ${ }^{14}$.

Os principais mecanismos de ação e efeitos biológicos dos lasers terapêuticos no tratamento da acne vulgar estão resumidos no quadro 2 , logo a seguir.

Quadro 2. Principais mecanismos de ação e efeitos biológicos dos lasers no tratamento da acne vulgar.

\begin{tabular}{|l|l|}
\hline \multicolumn{1}{|c|}{ Mecanismos de Ação } & \multicolumn{1}{|c|}{ Efeitos Biológicos } \\
\hline Fotodestruição ou & $\begin{array}{l}\text { Efeito fototérmico, formando calor, sendo } \\
\text { capaz de destruir o alvo tecidual atingido, } \\
\text { destacando-se o efeito antimicrobiano sobre a } \\
\text { bactéria P. acnes. } \\
\text { Redução da secreção de sebo pelas glândulas } \\
\text { sebáceas. } \\
\text { Na terapia fotodinâmica, o efeito antimicro- } \\
\text { biano pode ser atingido quando uma droga } \\
\text { fotossensibilizadora é ativada por uma luz laser } \\
\text { de baixa intensidade, gerando substâncias que } \\
\text { podem danificar ou destruir a célula alvo. }\end{array}$ \\
\hline Fototermólise & $\begin{array}{l}\text { Induz rompimento de ligações moleculares e } \\
\text { destruição do alvo tecidual pelo calor. } \\
\text { Aumenta a temperatura cutânea no local irra- } \\
\text { diado, estimulando o processo de neocolagêne- } \\
\text { se e remodelação dérmica. } \\
\text { Efeito analgésico, antimicrobiano, anti-inflama- } \\
\text { tório e cicatrizante. } \\
\text { Redução da secreção de sebo pelas glândulas } \\
\text { sebáceas. } \\
\text { Aumento da microcirculação local, vasodila- } \\
\text { tação e aumento da permeabilidade vascular, } \\
\text { aumento da drenagem linfática. }\end{array}$ \\
\hline a
\end{tabular}

Induz efeitos fotoquímicos e fitoelétricos capazes de modular atividades intra e extracelulares. Ativação de fibroblastos, melhora do metabolismo tecidual na área tratada e neocolagênese. Ativação de linfócitos, ativação de mastócitos, aumento na produção de ATP mitocondrial e a proliferação de vários tipos de células.

Fotobiomodulação $\quad$ Regulação positiva da produção celular dérmica da citocina TGF- $\beta$, a qual reduz a inflamação e estimula a neocolagênese.

Efeito analgésico, anti-inflamatório e cicatrizante.

Aumento da microcirculação local, vasodilatação e aumento da permeabilidade vascular, aumento da drenagem linfática (efeito antiedematoso)

Fonte: Paschoal \& Ismael ${ }^{4}$; Jih \& KimYai-Asadi ${ }^{5}$ Cohen et al.. $;$; Jagdeo et al. ${ }^{12}$; Oliveira et al. ${ }^{13}$; Lins et al. ${ }^{14}$

A atividade bactericida do laser é um fator muito relevante para obter êxito na laserterapia. As porfirinas produzidas pelo Propionibacterium acnes absorvem a luz no espectro visível. Em sua maioria são coproporfirina III, essa fotoexcitação promove a eliminação das bactérias $P$. acnes $^{4}$. A representação dos comprimentos de ondas eletromagnéticas de luz está apresentada na figura 2 .

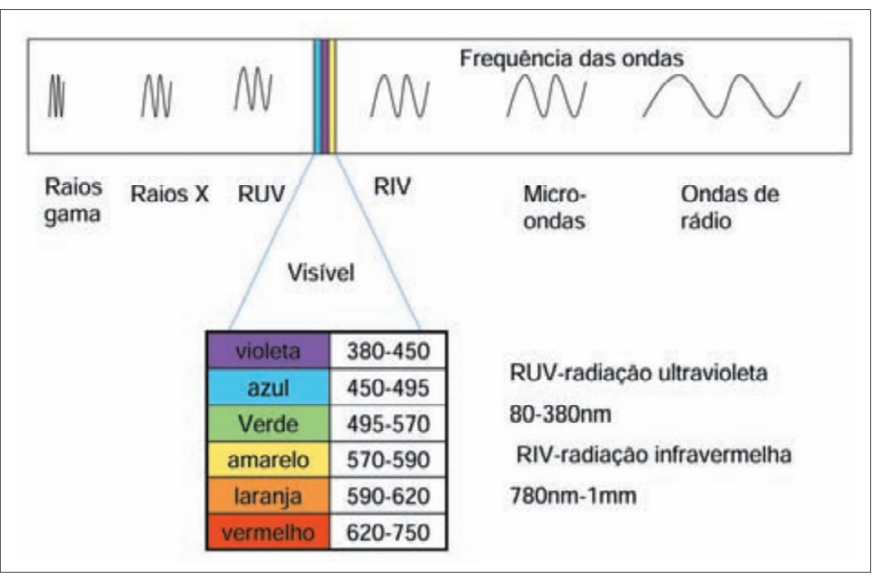

Figura 2. Espectro de luz visível e seus respectivos comprimentos de onda no espectro eletromagnético.

Fonte: Adaptado de Catorze ${ }^{15}$.

\section{Tipos de Laser utilizados no tratamento da Acne vulgar}

O espectro de luz visível vai dos 380 até os $750 \mathrm{~nm}$. Em geral quanto maior é o comprimento de onda maior é a penetração nos tecidos ${ }^{15,16}$. Os comprimentos de onda de luz laser utilizados no tratamento da acne vulgar variam 
de 532 a $10.600 \mathrm{~nm}$. Lasers de comprimento de onda mais curtos têm como alvo a epiderme e a derme superficial, e o componente vascular, enquanto os lasers de comprimento de onda mais longos, infravermelhos, têm como alvo as glândulas sebáceas ${ }^{6,15,16}$. Os principais tipos de Laser utilizados no tratamento da acne vulgar e seus respectivos benefícios são apresentados na tabela 1.

Tabela 1. Principais tipos de laser utilizados no tratamento da acne vulgar e seus benefícios terapêuticos.

\begin{tabular}{|c|c|c|}
\hline Tipos de laser & Frequência (nm) & Benefícios \\
\hline Pulsed Dye Laser (PDL) & $585-595$ & $\begin{array}{l}\text { Apresenta atividade anti-inflama- } \\
\text { tória, anti-eritematosa, microbicida, } \\
\text { cicatrizante, estimula a neocola- } \\
\text { gênese. }\end{array}$ \\
\hline Infravermelho & $808-980$ & $\begin{array}{l}\text { Rejuvenescimento facial e flacidez } \\
\text { cutânea. }\end{array}$ \\
\hline Nd:YAG & $532-1064$ & $\begin{array}{l}\text { Atividade microbicida, anti-infla- } \\
\text { matória e cicatrizante. }\end{array}$ \\
\hline Q- switched & $532-1064$ & $\begin{array}{l}\text { Apresenta atividade anti-inflama- } \\
\text { tória, microbicida, cicatrizante e } \\
\text { rejuvenescedora. }\end{array}$ \\
\hline Diodo & $810-1450$ & $\begin{array}{l}\text { Controle da secreção de sebo pelas } \\
\text { glândulas sebáceas, estimula a } \\
\text { neocolagênese. }\end{array}$ \\
\hline CO2 Fracionado & 10.600 & $\begin{array}{l}\text { Atua estimulando o processo de } \\
\text { cicatrização, elimina cicatrizes } \\
\text { e promove rejuvenescimento } \\
\text { cutâneo. }\end{array}$ \\
\hline
\end{tabular}

Fonte: Babilas ${ }^{3}$; Pascoal \& Ismael ${ }^{4}$; Antônio ${ }^{6}$; Catorze $^{15}$; Park ${ }^{17}$; Voravutinon ${ }^{18}$.

A fototerapia no que diz respeito à luz azul apresenta efeito positivo na acne. Esse laser pode reduzir a acne, pois a luz visível na faixa do azul compreende efeito fotodestrutivo no $P$. acnes. Foi constatado que a irradiação do $P$. acnes com UVA e luz azul provoca modificação no $\mathrm{pH}$ intracelular, deteriorando o influxo transmembrana de proteínas e ocasionando efeito nocivo nessa bactéria. A disseminação de colônias de P. acnes in vitro com luz azul visível origina a fotoexcitação das porfirinas bacterianas endógenas, produção de oxigênio e posterior destruição bacteriana ${ }^{4,17}$.

O uso combinado do laser de luz azul e do de luz vermelha por suas propriedades antimicrobianas e anti-inflamatórias, respectivamente, age de forma sinérgica. Essa combinação, utilizada no tratamento da acne, tem demonstrado ser uma opção promissora além de segura ${ }^{4,17}$.

\section{Cuidados no uso do Laser Terapêutico em \\ Procedimentos Estéticos}

Cada paciente deve ser avaliado e um protocolo específico traçado para o tratamento. O local do tratamento deve ser previamente higienizado. $O$ ângulo de incidência para aplicação de laser deve sempre estar localizado sobre à área de aplicação; o profissional e paciente devem estar usando proteção ocular específica. Em relação ao protocolo de irradiação, a utilização dos lasers pode diferir quanto ao tipo de lesão tecidual, à potência e dose utilizada e, também, quanto ao modo, tempo de irradiação e número de aplicações ${ }^{4,7,19}$.

Antes de iniciar o tratamento deve ser feita a anamnese do paciente e apontar todos os cuidados que o mesmo deve tomar antes, durante e após o procedimento. O profissional deve estar capacitado para realizar o procedimento, tanto profissional quanto paciente devem usar óculos de proteção, a sala em que for realizado os procedimentos com laser devem estar sinalizadas $4,7,19$.

\section{Contraindicações}

O laser tem diferentes aplicações clínicas, seja para tratar acne, manchas na pele ou cicatrizes, reparo de feridas. Porém também possui suas contraindicações, não podendo ser aplicado sobre útero gravídico, neoplasias, tratamento direto sobre o olho, aplicar sobre infecções ativas (herpes zoster), sobre as gônodas (ovários e testículos), tratamento sobre áreas fotossensíveis ou fotossensibilizadas da pele, sobre áreas hemorrágicas, áreas com aplicação de toxina botulínica, na esclerodermia, indivíduos com pressão arterial descompensada ${ }^{20}$.

Também é contraindicada em casos de tumor maligno localizado ou irradiado, sobre a glândula tireoide, nos casos de epilepsia e hipersensibilidade à luz ${ }^{21}$.

\section{Reações Adversas}

A terapêutica com o laser pode ocasionar dor, petéquias e eritema leves após as aplicações. Depende muito da sensibilidade de cada paciente, nem sempre são notadas tais alterações cutâneas. Não foram levantados efeitos adversos mais graves $5^{6,17,20}$.

\section{Eficácia da Laserterapia}

A laserterapia tem se mostrado muito eficaz no tratamento da acne vulgar. Além de tratar a acne em si, reduz o processo inflamatório e minimiza as cicatrizes ocasionadas pela acne. É efetiva, pois atua diretamente na P. acne, bactéria que causa a acne. É um tratamento que não apresenta efeitos colaterais como outros convencionais $\mathrm{s}^{7,13,17,18}$. Estudos clínicos demonstram que todas as tecnologias podem ser mais ou 
menos eficazes, dependendo dos parâmetros e técnicas utilizadas no tratamento de lesões da acne $\mathrm{e}^{3,17,18}$.

Estudos demonstraram que os lasers ablativos como o $\mathrm{CO}_{2} \mathrm{e}$ Er:YAG são mais eficazes para cicatrizes atróficas graves de acne, enquanto lasers não ablativos, como os fracionários de 1550 e $1540 \mathrm{~nm}$ ou laser de $755 \mathrm{~nm}$, são mais indicados em pacientes com cicatrizes leves/moderadas. Os laser PDL $585 \mathrm{~nm}$ e Alexandrita a $755 \mathrm{~nm}$ e lasers $1064 \mathrm{Nd}$ : YAG podem ser utilizado para cicatrizes com eritema/pigmentação $0^{3,17,18}$. Alguns estudos que evidenciam a eficácia da laserterapia no tratamento da acne vulgar são apresentados e resumidos na tabela 2 .

Tabela 2. Estudos que comprovam a eficácia da laserterapia no tratamento da acne vulgar.

\begin{tabular}{|c|c|c|c|}
\hline Tipos de laser & $\begin{array}{l}\text { Características } \\
\text { do Estudo }\end{array}$ & Resultados & Referência \\
\hline $\begin{array}{l}\text { Fracionado } \\
\text { não ablativo } \\
1.340 \mathrm{~nm}\end{array}$ & $\begin{array}{c}\text { Estudo } \\
\text { Prospectivo }\end{array}$ & $\begin{array}{l}\text { Diminuição das lesões acneicas, } \\
\text { do infiltrado inflamatório linfo- } \\
\text { citário, e organização das fibras } \\
\text { colágenas. }\end{array}$ & 6 \\
\hline $\begin{array}{l}\text { IR } \\
\text { (Infravermelho) }\end{array}$ & $\begin{array}{c}\text { Estudo } \\
\text { Prospectivo }\end{array}$ & $\begin{array}{l}\text { Observou-se melhora do local } \\
\text { da lesão, clareamento, diminui- } \\
\text { ção do volume de sebo e da } \\
\text { acne, redução da oleosidade na } \\
\text { área tratada e redução do qua- } \\
\text { dro álgico na região das lesões }\end{array}$ & 19 \\
\hline $\begin{array}{l}\text { Laser luz azul } \\
407 \text { a } 420 \mathrm{~nm}\end{array}$ & $\begin{array}{c}\text { Estudo } \\
\text { Prospectivo }\end{array}$ & $\begin{array}{l}\text { Redução do número de lesões } \\
\text { de acne graus Il e Ill e com } \\
\text { menos efeitos adversos quando } \\
\text { comparado ao peróxido de } \\
\text { benzoíla }\end{array}$ & 22 \\
\hline $\begin{array}{l}\text { Laser PDL } \\
595 \mathrm{~nm}\end{array}$ & $\begin{array}{l}\text { Estudo Clínico } \\
\text { Prospectivo }\end{array}$ & $\begin{array}{l}\text { Redução significativa do núme- } \\
\text { ro de lesões de acne nos locais } \\
\text { tratados }\end{array}$ & 18 \\
\hline $\begin{array}{l}\text { Laser PDL } \\
595 \text { nm e } 1550 \\
\text { nm fracionado e } \\
\text { não ablativo }\end{array}$ & $\begin{array}{l}\text { Estudo clínico } \\
\text { piloto, rando- } \\
\text { mizado }\end{array}$ & $\begin{array}{l}\text { Melhora significativa do eritema } \\
\text { da face dos pacientes }\end{array}$ & 17 \\
\hline $\begin{array}{l}\mathrm{HeNe} \\
632,8 \mathrm{~nm}\end{array}$ & $\begin{array}{c}\text { Estudo } \\
\text { Prospectivo }\end{array}$ & $\begin{array}{l}\text { Melhora no processo inflamató- } \\
\text { rio, clareamento de manchas, ole- } \\
\text { osidade, cicatrização e redução } \\
\text { na manifestação de novas lesões }\end{array}$ & 23 \\
\hline $\begin{array}{l}\text { Laser luz azul } \\
415 \mathrm{~nm}\end{array}$ & Ensaio clínico & $\begin{array}{l}\text { As lesões de acne reduziram } \\
\text { em } 64 \%\end{array}$ & 24 \\
\hline Diodo $1450 \mathrm{~nm}$ & $\begin{array}{c}\text { Estudo } \\
\text { Observacional }\end{array}$ & $\begin{array}{l}\text { Houve } 83 \text { \% na diminuição das } \\
\text { lesões ao fim de um tratamento } \\
\text { que durou de } 4 \text { a } 6 \text { semanas }\end{array}$ & 5 \\
\hline $\begin{array}{l}\text { Led azul } 470 \mathrm{~nm} \\
\text { e laser vermelho } \\
660 \mathrm{~nm}\end{array}$ & $\begin{array}{l}\text { Estudo } \\
\text { transversal } \\
\text { observacional, } \\
\text { descritivo }\end{array}$ & $\begin{array}{l}\text { Redução significativa no nú- } \\
\text { mero de comedões, pústulas e } \\
\text { pápulas após o tratamento }\end{array}$ & 25 \\
\hline
\end{tabular}

Assunção ${ }^{23}$, realizou um estudo onde obteve bons resultados com a utilização do laser HeNe com comprimento de onda de 632,8 nm de emissão contínua. Obteve melhora no processo inflamatório, clareamento de manchas, oleosidade, cicatrização e redução na manifestação de novas lesões. Tzung ${ }^{26}$, desenvolveu um estudo com 31 pacientes onde obteve resultado satisfatório na acne grau $\mathrm{ll}$ em $52 \%$ desses pacientes. Foi utilizada a luz azul em um lado da face e o outro lado foi usado como controle.

Silva ${ }^{19}$, realizou uma pesquisa com 10 pacientes acneicos com idade de 14 a 23 anos, cor branca, a acne variava do grau II ao VI que não faziam uso de nenhum medicamento para tratar a acne. No estudo foi utilizado um aparelho de laserterapia da marca laser IR, uma caneta laser 904 laser probe optical power output de $30 \mathrm{~mW}$ wavelenght. $O$ tratamento não foi realizado em toda a face a fim de observar o resultado obtido e contrapor com as áreas não tratadas. Observouse melhora do local da lesão, clareamento, diminuição do volume de sebo e da acne, redução da oleosidade na área tratada e redução do quadro álgico na região das lesões.

Podemos destacar também um ensaio clínico que utilizou o dispositivo de luz azul, onde foram tratados 30 pacientes. As sessões eram realizadas duas vezes por semana durante 5 semanas. Os benefícios foram observados após uma semana. As lesões de acne reduziram em $64 \%{ }^{24}$.

Em todos os estudos avaliados observou-se resolução do processo inflamatório, redução da oleosidade da pele, clareamento das manchas ocasionadas pela acne, efetividade na cicatrização tecidual e diminuição no surgimento de novas lesões.

\section{Medidas profiláticas para prevenção e controle da Acne Vulgar}

A profilaxia para prevenção e controle da acne está associada à dieta, hábitos de vida, higienização cutânea e estresse, dentre outros fatores. Há pouco tempo, foi identificada uma relação entre a introdução de alimentos com carga glicêmica elevada e a patogênese da acne, mediante a hiperinsulinemia provocada por tais alimentos ${ }^{27}$.

Evidências científicas comprovam que a acne está associada à limpeza inadequada da pele. Deve-se utilizar um cosmético ideal para cada tipo de pele, o paciente deve ser aconselhado a lavar e secar suavemente a região afetada, uma vez ao dia, com agente de limpeza próprio e suave. Existe uma correlação entre a acne e períodos de estresse emocional, então saber controlar ou evitá-la é importante para a prevenção de tal afecção. Manter hábitos saudáveis, por exemplo, atividade física regular, procurar momentos de 
descanso para evitar o estresse previnem o aparecimento da acne 27 .

\section{Conclusão}

A laserterapia para o tratamento da acne vulgar é uma alternativa eficaz pois apresenta resultados satisfatórios. $\mathrm{O}$ tratamento quase não apresenta efeitos colaterais e reações adversas importantes, seu efeito anti-inflamatório e cicatrizante, juntamente com a melhora da cicatriz, torna esse tratamento completo. Estudos demonstram que a laserterapia melhora quadros de acne, em especial inflamatória, de graus leve a moderado e que essa melhora pode-se manter ao longo de vários meses. Os efeitos colaterais são em geral poucos e bem tolerados.

Existem poucos estudos clínicos brasileiros demonstrando o uso e eficácia do laser terapêutico no tratamento de lesões da acne vulgar. Alguns estudos demonstraram que o tratamento da acne vulgar com laser de luz azul foi um método eficaz para a redução do número de lesões de acne graus II e III e que, praticamente, não apresenta efeitos adversos quando comparado com tratamento medicamentoso. Esse fato confere ao laser uma opção real de tratamento, principalmente para os pacientes com contraindicação aos outros métodos de tratamento. Novos estudos com a associação do laser com outras terapias devem ser realizados com o intuito de potencializar resultados por combinação de terapias.

Vários tipos de lasers são utilizados para o tratamento de acne vulgar. Embora sejam eficazes, em geral, diferem em termos de efeitos colaterais e resultados clínicos, dependendo do fototipo de pele e do tipo de cicatriz da acne do paciente, cabendo ao profissional escolher o melhor tipo de laser para cada tratamento de acne. Existem algumas deficiências na maior parte dos estudos clínicos, como a falta de estudos randomizados, duplo-cegos em larga escala e ferramentas uniformes de avaliação objetiva. Em alguns estudos, tipos de pele, tipos de cicatrizes de acne e fatores de variação genética relacionados (diferenças individuais) não foram considerados em diferentes estudos. Estudos clínicos rigorosos e contínuos para as novas modalidades de laser que entram no mercado são críticos para garantir sua segurança e eficácia no tratamento da acne e no desenvolvimento de protocolos terapêuticos apropriados.

\section{Referências}

1. Figueiredo A, Massa A, Picoto A, Soares AP, Basto AS. et al. Avaliação e tratamento do doente com acne - Parte I: Epidemiologia, etiopatogenia, clínica, classificação, impacto psicossocial, mitos e realidades, diagnóstico diferencial e estudos complementares. Rev Port Clin Geral. 2011;27:59-65.

2. Carvalho A, Mourão A, Assunção C, Fonseca C, Gama $D$, et al. Acne: prevalência e fatores associados. Patient Care. Edição Portuguesa. 2010;15(156):59-65.

3. Babilas P, Schreml S, Eames T, Hohenleutner U, Landthaler M, Hohenleutner S. Experience with non-ablative fractional photothermolysis with a dualmode laser device $(1,440 / 1,320 \mathrm{~nm})$ : no considerable clinical effect on hypertrophic/acne scars and facial wrinkles. Lasers Med Sci. 2011;26(4):473-79.

4. Pascoal FM, Ismael LPPB. A ação da luz no tratamento da acne vulgar. Surg Cosmet Dermatol. 2010;2(2):117-123.

5. Jih MH, Kimyai-Asadi A. Laser treatment of acne vulgaris. Semin Plast Surg. 2007;21(3):167-74.

6. Antônio $C R$, Antônio JR, Oliveira GB, Trídico LA, Borim MP. Uso do laser fracionado não ablativo NdYAP 1. $340 \mathrm{~nm}$ no tratamento da acne nódulo cística resistente a isotretinoína. Surg Cosmet Dermatol. 2013;5(4):310-314.

7. Cohen BE, Brauer JA, Geronemus RG. Acne scarring: a review of available therapeutic lasers. Lasers Surg Med. 2016;48(2):95-115.

8. Vanzin SB, Camargo CP. Entendendo CosmecêuticosDiagnósticos e Tratamentos. 2 Edição São Paulo: Livraria Santos; 2011.

9. Araújo APS, Delgado DC, Marçal R. Acne diferentes tipologias e formas de tratamento. VII Encontro Internacional de Produção Científica, 2011. Disponível em: http://www.cesumar.br/prppge/pesquisa/epcc2011/ or2.php .Acesso em 14 de fevereiro de 2020.

10. Costa CS, Bagantin E. Evidências sobre o tratamento da acne. São Paulo Med. J. [online]. 2013,131(3):193-197.

11. Hill P, Owens P. Milady laser e luz. Editora Genegage Learning Edições Ltda. 2017.

12. Jagdeo J, Austin E, Mamalis A, Wong C, Ho D, Siegel DM. Light-emitting diodes in dermatology: a systematic review of randomized controlled trials. Lasers Surg Med. 2018;50(6):613-28.

13. Oliveira MS. Elaboração de um modelo para implantação de um programa de fisioterapia dermato-funcional com laserterapia para o atendimento na rede SUS para adolescentes com cicatriz de acne. 2011. Disponível em: <http://www.portalbiocursos.com. br>. Acesso em: 05 Abr2020.

14. Lins RDAU, Lucena KCR, Granville-Garcia AF, Dantas EM, Catão MHCV, Carvalho Net LG. Efeitos bioestimulantes do laser de baixa potência no processo de 
reparo. Na Bras Dermatol. 2010;85(6):849-55.

15. Catorze MG. Laser: fundamentos e indicações em dermatologia. Med Cutan Iber Lat Am. 2009;37(1): 5-27.

16. Alexiades $M$. Laser and light-based treatments of acne and acne scarring. Clin Dermatol. 2017;35:183-89.

17. ParkKY, Ko EJ, Seo SJ, Hong CK. Comparison of fractional, nonablative, 1550-nm laser and 595-nm pulsed dye laser for the treatment of facial erythema resulting from acne: A split-face, evaluator-blinded, randomized pilot study. J Cosmetic Laser Ther. 2014;16:120-23.

18. Voravutinon N, Rojanamatin J, Sadhwani D, lyengar $\mathrm{S}$, Alam M. A comparative split-face study using different mild purpuric and subpurpuric fluence level of 595-nm pulsed-dye laser for treatment of moderate to severe acne vulgaris. Dermatol Surg. 2016;42 (3):403-409.

19. Silva S, Costa JM, Vinade IA. Laserterapia como tratamento estético. 2009. Disponível em: <http:///www. http://fisio-tb.unisul.br>. Acesso em: 10 Abr 2019.

20. Lopez JC, Pereira LP, Bacelar IA. Laser de baixa potência na estética-revisão de literatura. Revista em foco. 2018;10:429-437.

21. Moshkovska T, Mayberry J. It is time to test low level laser therapy in Great Britain. PostgradMed J. 2005;81(957):436-441.

22. Arruda LHF, Bastos Filho A, Kodani V, Mazaro CB. Estudo clínico, prospectivo, aberto, randomizado e corporativo para avaliar a segurança e a eficácia da luz versus peróxido de benzoíla $5 \%$ no tratamento de acne inflamatória II E III. An Bras Dermatol. 2009;84(5):463-8.

23. Assunção D. Tratamento fisioterapêutico da acne por meio de laser. Rev. Fisioterapia em Movimento. 2006;16(4):11-6.

24. Nestor MS, Sweson N, Macri A. Physical modalities (devices) in the management of acne. Dermatol. Clin. 2016;34(2):215-23.

25. Alba MN, et al. Comparação clínica da casca de ácido salicílico e fototerapia com laser de LED para o tratamento da acne vulgar em adolescentes. Journal of Cosmetic and Laser Therapy. 2017;19(1):49- 53.

26. Tzung TY, Wu KH, Huang ML. Light phototherapy in the treatment of acne. Photodermatol Photoimmunol Photomed. 2004;20:266-269.

27. Silva AMF, Costa FP, Moreira M. Acne vulgar: diagnóstico e manejo pelo médico de família e comunidade. Revista Brasileira de Medicina de Família e Comunidade. 2014;9(30):54-63. 